\title{
Cancer Pain Management: Strategies for Safe and Effective Opioid Prescribing
}

Presented by Judith A. Paice, PhD, RN

\begin{abstract}
Although controversial in recent years, the use of opioid analgesics is a fundamental component of the management of patients with malignant pain. Decisions about whether to initiate opioid therapy require comprehensive patient assessment and a great deal of compassion, with an eye toward achieving a safety balance among patients, prescribers, and the community. At the NCCN 21st Annual Conference, Judith Paice, PhD, RN, reviewed the basics of pain assessment, the dangers of undertreatment and overtreatment, goals of pain management, and practical strategies for navigating through the continuum of pain and substance abuse.
\end{abstract}

J Nat/ Compr Canc Netw 2016;14(5.5):695-697

How do you provide good pain control and, at the same time, ensure that our patients are safe?" asked Judith A. Paice, $\mathrm{PhD}$, RN, Director of the Cancer Pain Program, Division of Hematology-Oncology, and Research Professor of Medicine, Feinberg School of Medicine, Robert H. Lurie Comprehensive Cancer Center of Northwestern University. "We've learned to use opioids a little bit more judiciously [than in the past], but the pendulum may have swung a little bit too far in the direction of using opiods in people who may not be the best candidates or using them at higher doses than they should be," continued Dr. Paice, who is also Past President of the American Pain Society and a member of the NCCN Guidelines Panel for Adult Cancer Pain.

\section{Basics of Pain Assessment}

"Pain is not just a change in the nervous system, there are deeply held beliefs and meanings associated with the individual's pain," revealed Dr. Paice. The basics of assessing pain include its onset, location, duration, qual-

\footnotetext{
Presented by Judith A. Paice, PhD, RN, Division of Hematology-Oncology, Feinberg School of Medicine, Robert H. Lurie Comprehensive Cancer Center at Northwestern University, Chicago, Illinois.

Dr. Paice has disclosed that she has no financial interests, arrangements, affiliations, or commercial interests with the manufacturers of any products discussed in this article or their competitors.

Correspondence: Judith A. Paice, PhD, RN, Robert H. Lurie Comprehensive Cancer Center of Northwestern University, 676 North St. Clair Street, Suite 850, Chicago, IL 60611. E-mail: j-paice@northwestern.edu
}

ity, intensity, and aggravating/alleviating factors. In addition, clinicians should take several other factors into consideration, such as quality-of-life issues, current/ previous medications, and comorbid conditions (which may place a patient at risk for drug misuse). Furthermore, patients should be asked about their goals for pain care. "Sometimes patients have extraordinarily unrealistic goals," admitted Dr. Paice, some perhaps expecting zero pain 24 hours a day, 7 days a week.

Pain assessment should delve deeper into potential risk factors for the abuse of pain medications, according to Dr. Paice. Current or past habits with regard to alcohol and tobacco use should be explored. Environmental and genetic exposure to substance abuse disorder in family or friends represents another risk factor, as does a history of sexual abuse. "Frankly, I am surprised by how many patients answer that they have been sexually abused," acknowledged Dr. Paice.

The types of pain and the appropriate pharmacologic intervention were briefly discussed (Figure 1). For somatic (nociceptive) pain, nonopioids (including acetaminophen and nonsteroidal anti-inflammatory drugs) and opioids are indicated. For patients with neuropathic pain, opioids at perhaps higher doses would be an option. Adjuvant analgesics (eg, antiepileptics, antidepressants, corticosteroids) are also indicated for neuropathic pain. Finally, for visceral pain, which represents a complex set of syndromes, there is not much evidence suggesting the best approach; therefore, opioids or corticosteroids are possibly indicated. 


\begin{tabular}{|l|l|}
\hline Type of Pain & Pharmacologic Interventions \\
\hline Somatic (nociceptive) & $\begin{array}{l}\text { Nonopioids } \\
\text { - Acetaminophen } \\
\text { - NSAIDs } \\
\text { Opioids }\end{array}$ \\
\hline Neuropathic & $\begin{array}{l}\text { Opioids (may require higher doses) } \\
\text { Adjuvant analgesics } \\
\text { - Antiepileptics }\end{array}$ \\
& $\begin{array}{l}\text { - Antidepressants } \\
\text { - Corticosteroids } \\
\text { - Local anesthetics } \\
\text { - NMDA antagonists }\end{array}$ \\
\hline Visceral & $\begin{array}{l}\text { Opioids } \\
\text { Corticosteroids } \\
\text { Adjuvant analgesics? }\end{array}$ \\
\hline
\end{tabular}

Figure 1. Quality of pain: treatment.

Abbreviation: NSAIDs, nonsteroidal anti-inflammatory drugs.

Dr. Paice stressed the importance of documenting any and all assessment findings. In fact, the 2016 NCCN Guidelines for Adult Cancer Pain include a reference to a tool that may help clinicians assess and document pain outcomes in patients with chronic pain receiving opioid therapy. ${ }^{2}$

\section{A Delicate Balance Between Undertreatment and Overtreatment}

Striking a balance between undertreating and overtreating cancer pain is complex, requiring a keen eye to patients at risk for both scenarios. Many patient groups may be at risk for underassessment and, as a result, are undertreated for their chronic pain; these groups include the elderly (aged $>65$ years), cognitively impaired individuals, those with mental health disorders, members of non-English-speaking minorities, long-term survivors, the underinsured or uninsured, and those with a current or past history of substance misuse. ${ }^{3}$

Interestingly, the profiles of these patient groups are essentially the same as those for patients at risk for overtreatment. With limited data on the longterm benefit of opioid therapy, Dr. Paice mentioned some of the dangers of overtreatment, including cognitive difficulties, depression, sexual dysfunction, respiratory depression, and overdose. Other, perhaps less well-known, adverse effects of opioids focus on quality-of-life issues, such as hormonal changes affecting libido and fertility, decreased bone health, fatigue, and suppression of testosterone. "We think more carefully now when we are embarking on a long-term plan of using opioids," Dr. Paice revealed.
A systematic review of the adequacy of analgesic therapy in patients with cancer suggested that the quality of pharmacologic pain management has improved since 1994, but much still needs to be done to meet the needs of this population. "Approximately one-third of patients still do not receive pain medication proportional to their pain intensity," Dr. Paice reported.

\section{Optimal Pain Management}

In the 2016 NCCN Guidelines for Adult Cancer Pain, the goals of pain management are referred to as the 4As: optimize Analgesia, optimize Activities of daily living, minimize Adverse effects, and avoid Aberrant drug-taking. To find the proper balance in aggressive pain management, Dr. Paice suggested keeping in mind 2 groups of patients: those with advanced disease and long-term survivors.

For those with advanced disease, escalation of opioids and adjuvant analgesics as well as referral for interventional therapies (ie, physical/occupational and cognitive behavioral) are indicated. ${ }^{3}$ For longterm survivors, pharmacologic therapies should be minimally used, with referral to multidisciplinary care playing a larger role. "Honestly, it [opioids] is not the right therapy for many people," admitted Dr. Paice.

\section{Pain and Substance Abuse}

There is a continuum of pain and substance use disorders; on one end are patients who clearly are not addicted, and on the other end are those who clearly have addiction issues. ${ }^{5}$ The middle and larger "gray 
zone" represents all of those "for whom we really don't know," added Dr. Paice. "We see this in clinic everyday." In the 2016 NCCN Guidelines for Adult Cancer Pain, a new bullet was added for assessing patients for misuse of pain medications: "Initial patient evaluation should include assessment of risk factors for aberrant use of pain medications by detailed patient evaluation and/or the use of screening tools."

Dr. Paice stressed the importance of ongoing compassionate assessment with regard to pain and substance use disorder. " Remember, this is a disease, not a character flaw."

Dr. Paice briefly discussed risk-stratification guidelines. Gourlay et $\mathrm{al}^{8}$ stated that by respectfully assessing patients and triaging them into different risk categories, "stigma can be reduced, patient care improved, and overall risk contained." Those who are at low risk of substance abuse often may be safely managed in primary care settings, with adherence monitoring at least annually. Those at moderate risk may be managed in consultation with appropriate specialist support, with adherence monitoring at least every 6 months and more frequent urine toxicology testing. For those at high risk, it is recommended that addiction specialists may be called in to handle pain management, with frequent (weekly or monthly) adherence monitoring.

Dr. Paice briefly addressed the differential diagnosis of aberrant drug-taking behavior. To begin, although patients who ask frequently for more pain medications may be misusing opioids, sometimes the issue may be more of insurance limits for filling prescriptions than addiction; therefore, Dr. Paice stressed the importance of asking questions and learning more. For instance, some of these patients may be "chemical copers" or using their pain medications to relieve other disorders (ie, anxiety, depression, sleep problems). Low treatment literacy may be an issue as well.

"One develops tolerance to the soporific or anxiolytic effects of the opioid," Dr. Paice explained. "We need to be very clear with patients that they can't take these medicines to treat their anxiety, make them feel a little less sad, or to help them sleep."
Dr. Paice encouraged clinicians to have an open discussion with patients suspected of abusing their pain medications, with a clear message that the goal is to balance pain control, function, and safety. She offered possible comments to open such difficult talks with patients: "We don't want to jeopardize your health. I am worried about your relationship with pain medications; using these medications to help you sleep is dangerous, so let's try other strategies for that."

Dr. Paice shared a few strategies for screening patients on opioids for aberrant behaviors. Prescribers can limit the amount of medication given at any one time by writing weekly prescriptions with fill-by dates, using pill counts, and maximizing other methods of pain control besides opioids. ${ }^{6}$ Furthermore, prescription drug monitoring programs may be an effective way to verify medication use, dose, and next refill date. "I use urine toxicology to see whether the patient is taking the drug I have prescribed," shared Dr. Paice.

Patients on prescription pain medications should be reminded of the dangers of substance abuse in the community and instructed on safe medication storage practices. These medications should not be left out or kept in unlocked medicine cabinets, because they have become primary sources of diversion and require safe handling and disposal.

\section{References}

1. Dev R, Parsons HA, Palla S, et al. Undocumented alcoholism and its correlation with tobacco and illegal drug use in advanced cancer patients. Cancer 2011;117:4551-4556.

2. Passik SD, Kirsh KL, Whitcomb L, et al. A new tool to assess and document pain outcomes in chronic pain patients receiving opioid therapy. Clin Ther 2004;26:552-561.

3. Paice JA, Von Roenn JH. Under- or overtreatment of pain in the patient with cancer: how to achieve proper balance. J Clin Oncol 2014;32:1721-1726.

4. Greco MT, Roberto A, Corli O, et al. Quality of cancer pain management: an update of a systematic review of undertreatment of patients with cancer. J Clin Oncol 2014;32:4149-4154.

5. Ballantyne JC. Assessing the prevalence of opioid misuse, abuse, and addiction in chronic pain. Pain 2015;156:567-568.

6. Swarm RA, Anghelescu DL, Benedetti C, et al. NCCN Clinical Practice Guidelines in Oncology: Adult Cancer Pain. Version 2.2016. Accessed April 20, 2016. To view the most recent version of these guidelines, visit NCCN.org.

7. Whitcomb LA, Kirsh KL, Passik SD. Substance abuse issues in cancer pain. Curr Pain Headache Rep 2002;6:183-190.

8. Gourlay DL, Heit HA, Almahrezi A. Universal precautions in pain medicine: a rational approach to the treatment of chronic pain. Pain Med 2005;6:107112. 